\title{
Returning mail-order goods: analyzing the relationship between the rate of returns and the associated costs
}

\author{
Björn Asdecker ${ }^{1}$
}

Received: 15 November 2014/ Accepted: 20 July 2015/Published online: 31 July 2015

(C) The Author(s) 2015. This article is published with open access at Springerlink.com

\begin{abstract}
Mail-ordering, particularly on the internet, has continually grown in importance over the last few years. This trend is expected to continue with no apparent end in sight. Liberal return policies have significantly contributed to this development by strengthening trust in both the individual retailers and the sales channel in general, but they do come at a price. This article is the first to systematically analyze the relation between the rate of returns and the associated costs. A circular model for the sales and returns process reveals a disproportionate relation between the two, which is further amplified once depreciation is considered. The model may serve decision-makers as an easy-to-use tool to systematically evaluate preventive returns management measures such as avoidance and gatekeeping.
\end{abstract}

Keywords Product returns - Mail-order business · Distance selling · Rate of returns · Product return costs

\section{Introduction}

Mail-ordering has been growing rapidly over the last decade [1]. For the most part, this development can be attributed to the increasing acceptance of online shopping. Obviously, e-tailers have done a good job in reducing the risks customers commonly associate with mail-order businesses. One common way of building trust and

Björn Asdecker

bjoern.asdecker@uni-bamberg.de

1 Lehrstuhl für Betriebswirtschaftslehre insb. Produktion und Logistik, Otto-Friedrich-Universität Bamberg, Feldkirchenstr. 21, 96052 Bamberg, Germany increasing the likelihood of ordering is the establishment of liberal return policies. Well-known examples of this strategy are the fashion retailers Zalando (www.zalando.com) and Zappos (www.zappos.com), which allow customers to return merchandise for up to 365 days at no charge. However, returns also entail a variety of direct and indirect costs.

Direct costs include administrative and processing costs [2]. Additional expenses occur if the merchandise is received in a deteriorated condition. In these cases, retailers must bear the costs of new packaging, reconditioning, value depreciation, and waste disposal. In the following, these costs are referred to as disposition costs. Returns caused by poor customer experiences, such as poor fulfillment or product quality, may indirectly harm satisfaction as well as loyalty, weaken the retailer's reputation, and decrease the customer's lifetime value [2-4]. Indirect costs represent potential damages to customer relations and are therefore difficult to quantify. These costs are closely related to but should not be confused with the consumer's return effort, which is occasionally referred to as "hassle costs" [e.g., 5, 6]. Consumers choose the return option if they perceive the purchase price minus the transaction costs to be larger than the remaining product value after the return period $[6,7]$. Transaction costs can involve hassles such as compromising one's free time and psychological well-being. They can also take the form of restocking fees or excluding shipping costs from reimbursement [5, 8]. Greater hassle increases the perceived transaction costs, which, on the one hand, may damage customer satisfaction but, on the other hand, leads to more customers retaining their purchases instead of sending them back [3]. Consequently, the customer's hassle costs reduce the retailer's direct costs but raise the indirect return costs. 
The expenses a distance seller ultimately must bear depend on the range of available legal options. In the USA, no federal law governs the issue of product returns. Except for a few state laws that require retailers to conspicuously disclose the policy employed before the transaction is completed [e.g., 9, 10], sellers can freely establish their own policy. That is, distance sellers may refuse returns, charge restocking fees, or not reimburse shipping rates. In contrast, the European Union grants consumers comprehensive revocation rights. With a few exceptions, consumers may withdraw from their purchase for any reason within 14 days of the purchase. The seller must fully refund the buyer, including any shipping charges paid. The buyer must bear the costs of returning the goods only if the seller disclosed this policy ahead of the transaction. Otherwise, the products are collected and transported at the trader's expense [11]. Hence, the possibility of shifting direct costs from the retailer to the consumer is much more limited in the European Union than in the USA.

Irrespective of the legal environment, both direct and indirect costs emphasize the need for effective returns management. Rogers et al. [12] define returns management as the "[...] process by which activities associated with returns, reverse logistics, gatekeeping, and avoidance are managed within the firm and across key members of the supply chain." Consequently, returns management is composed of the efficient handling and processing of returns as well as preventive measures to reduce the number of incoming returns [13].

Avoidance involves all proactive measures to eliminate the reasons why goods are returned [12]. This includes enhancing product quality, streamlining of the product range, reducing delivery time, providing comprehensive product information, and offering financial incentives that lead to more informed ordering decisions. In contrast, gatekeeping disrupts or prevents orders from entering the returns channel [12]. Thus, mail-order businesses provide refunds that do not require the item to be returned, increase a consumer's transaction costs, or suspend deliveries.

Since many retailers consider their return rates and costs excessively high, they are interested in ideas and technologies to reduce return rates. Certain publications even consider preventive returns management the most critical issue $[2,14,15]$. The success of several technology startups demonstrates the need for innovative concepts and tools. Examples are Upcload (www.upcload.com) and Sproov (www.sproov.com), both of which offer online clothing fitting advisors. Their services may reduce sizerelated product returns by $12-60 \%$ [16]. Shoefitr (www. shoefitr.com), which was recently purchased by Amazon [17], offers similar business intelligence for shoes. This application requires the customer's current model and size to calculate the likelihood that the new shoe will fit as well; it then recommends the best-fitting size.
However, preventive returns management is not free. Decision-makers have to wonder whether it is worth it. Will the implementation of an online fitting tool, the production of high-definition product videos, or faster delivery be worthwhile? To answer these questions, it is crucial to understand the relation between the returns rate and the associated expenditures. Little research has been dedicated to this topic despite its pivotal role for the competitiveness of mail-order businesses. Therefore, this article attempts to contribute to the following research questions:

- What type of relation exists between the returns rate and the associated costs?

- What happens once the effects of deterioration because of damages incurred before the return deadline and/or during transportation are taken into account?

- What strategic implications does this relation have on how to best arrange the returns management?

The article is structured as follows. The upcoming section summarizes the relevant literature on this topic and provides a deeper understanding of the decision-making context. Next, the typical mail-ordering sales process is modeled in a circular fashion that lends itself to the examination of the returned goods' cost impact. To increase its practical relevance, the basic model is then extended with the possibility of deterioration during the revocation period. In the following, the model results are discussed and strategic recommendations on how to best arrange the returns management process are provided. Finally, a conclusion and an outlook on future research are given.

\section{The literature review and background}

Over the last decade, the literature on returns management has increased [13]. To structure the existing work, conceptual, empirical, and analytical contributions are distinguished, because very few papers deal with product returns in mail-ordering-related domains such as business-tobusiness returns or reverse logistics in other industries will also be considered.

\subsection{Conceptual understanding and empirical evidence}

Conceptually, Rogers et al. [12] describe a generic returns management process that enables businesses to efficiently handle returned products and to identify levers that reduce the quantity of incoming returns. The strategic subprocess suggests determining returns management goals and strategy, developing avoidance, gatekeeping and disposition guidelines, developing a returns network and flow options, 
developing credit rules, determining secondary markets, and developing a framework of metrics for performance measurement. On the operational end, return requests are received, routing is determined, returns are received, disposition is selected, consumers are credited, returns are analyzed, and performance is measured.

Another process is presented by Stock et al. [18]. This more operational approach is composed of five stages: (1) receive; (2) sort and stage; (3) process; (4) analyze; and (5) support. The process begins with returns arriving at the processing site, which is usually a centralized warehouse or distribution center. Next, the sort and stage activity prepares the efficient processing of incoming items. Thus, it is reasonable to identify and separate different product categories (e.g., fashion and consumer electronics) as they are likely to involve different processing. At the third stage, returns are transported to a processing station where qualified personnel open each item and separate the accompanying paperwork, which is often sent to customer service. Customers may be refunded at this stage if prepayments have been made. The fourth step involves examining each return thoroughly and determining the appropriate disposition option. Finally, the redistribution of repackaged, repaired, and refurbished products must be supported. As the authors observe, all of these activities incur significant direct costs [18].

Norek [19] adds that disposition costs depend heavily on the chosen recovery option because of different cost structures and required depreciation. According to that study, at least five asset recovery options exist. These are listed in descending order of revenue return as follows: (1) sell as new; (2) repair or repackage and resell as new; (3) repair or repackage and resell as used; (4) resell at a lower value to a salvage house; and (5) sell by the pound to a salvage house. Blackburn et al. [20] note that products with short sales cycles are threatened with additional costs through slow processing. The researchers refer to this as the "marginal value of time." In these cases, it may be economical to choose faster transportation and decentralized processing to minimize the time a product remains in the reverse pipeline to compensate for the value loss over time.

Empirically, some authors measure the costs of returned goods. Stock et al. [18] estimate return expenditures at \$30-35 per item for American mail-ordering. In Europe, shorter distances lead to lower transportation charges, which explain a slightly smaller financial impact. A study by IBI Research estimates the costs for processing, administrative work, and disposition at $20 €$ per return in the German mail-order market [21]. Asdecker/Weigel [22] provide a more detailed appraisal. A survey of 303 German mail-order businesses showed average processing and administrative costs of $7.93 €$ per return. The unit costs decline with company size; smaller companies deal with much higher expenses than their larger counterparts. The surveyed mail-order businesses claim that the average costs caused by the deterioration are $13.1 \%$ of the goods' value [22].

\subsection{Analytical modeling}

Analytical decision-making models that include merchandise returns and their associated costs represent the vast majority of relevant publications. Two categories can be distinguished: inventory planning and product recovery models. Fleischmann et al. [23] present an $(\mathrm{s}, \mathrm{Q})$-inventory model with returns. The researchers' conclusion is "[...] that the return-flow has rather little impact on the optimized expected average costs unless the return ratio is close to one, resulting in high on-hand inventory" [23]. Vlachos/Dekker [24] solve single-period newsvendor problems considering resalable product returns that arrive before the end of the selling season. They assume that products can only be resold once per selling period. However, in practice, products may be returned and reused several times within a season. Mostard/Teunter [25] eliminate this assumption by using a net demand approach. In addition, Mostard et al. [26] show that incomplete information regarding the demand distribution does not thwart a successful application. Chen/Bell [27] simultaneously examine profit-maximizing pricing and order quantity planning. Their article is based on a study by Anderson et al. [8] that claims that the probability of a return increases with a rise in the sale price. They solve this problem for single- and multiperiodic cases by assuming in the latter case that returns in period $t$ will be sold in the following period $t+1$ [27]. Despite integrating returns, all of these models rather optimize decision-making in the forward supply chain than in the backward supply chain. Product returns are viewed as a parameter that depends on the quantity sold in previous periods, not as a decision variable. Therefore, the existing models may not help to evaluate preventive returns management measures as examined in this paper.

The second category of mathematical models pursues the optimal product recovery strategy by improving acquisition, remanufacturing, and salvaging decisions [e.g., 28-30]. These contributions consider the quantity of product returns as a decision variable. Hence, these contributions are extremely useful to obtain the most from returns. However, particularly in mail-ordering, a major proportion of returns may be prevented or avoided before they actually occur, which would be the best option for many distance sellers. As Johnson [14] summarizes, "[t]he best return is no return." 


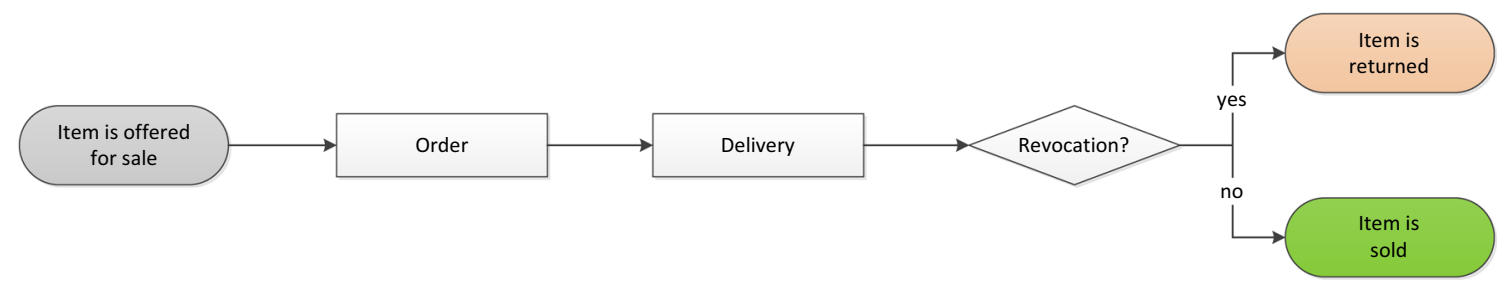

Fig. 1 Linear rendering of the sales process for an item

Table 1 Calculation of costs and contribution margin while considering returns for $n=20$ orders in accordance with Speights/Hilinski [31]

\begin{tabular}{lllll}
\hline Rate of returns $\beta$ & $0 \%$ & $20 \%$ & $50 \%$ & $100 \%$ \\
\hline Expenditures subject to $\beta: \beta \cdot(p-c+r)(\$)$ & 0 & 12.50 & 31.25 & 62.50 \\
Total costs: $d+\beta \cdot(p-c+r)(\$)$ & 27.50 & 40.00 & 58.75 & 90.00 \\
Contribution margin: $\mathrm{CM}_{\text {order }}(\beta)(\$)$ & 12.50 & 0 & -18.75 & -50.00 \\
Sum of contribution margins: $n \cdot \mathrm{CM}_{\text {order }}(\beta)(\$)$ & 250 & 0 & -375 & -1000 \\
\hline
\end{tabular}

A cost-benefit analysis of preventive returns management measures requires an understanding of the relation between the rate of returns and the associated costs. This type of examination has only been attempted in two articles $[31,32]$ that share one commonality: They view the order and the return as an isolated, onetime process that ends with the decision to either retain or return the goods (Fig. 1).

Accordingly, the vendor must bear the cost of returned goods $r$ (restocking cost) in addition to the distribution costs $d$, which consist of the customer acquisition costs as well as the packaging and shipping costs if paid by the retailer. If the customer wants to keep the goods, the company will realize the sales price $p$ minus the purchase price $c$ and the necessary distribution costs $d$. Consequently, the contribution margin $\mathrm{CM}$ of an order in relation to the rate of returns $\beta$ is calculated as follows:

$$
\begin{aligned}
\mathrm{CM}_{\text {order }}(\beta) & =(1-\beta) \cdot(p-c-d)-\beta \cdot(r+d) \\
& =p-c-d-\beta \cdot(p-c+r) .
\end{aligned}
$$

An application of this formula is shown by Speights/ Hilinski [31] in a typical example. The authors assign the parameter values $p=\$ 100, c=\$ 60, d=\$ 27.50, \quad r=$ $\$ 22.50$ and assume four scenarios, each encompassing 20 orders (refer to Table 1). Accordingly, a business with a rate of returns of $0 \%$ generates a contribution margin of $\$ 250$, which becomes negative as soon as $\beta$ crosses the $20 \%$ threshold. If none of the customers retain their ordered items $(\beta=100 \%)$, the company loses $\$ 1000$.

Mondragon et al. [32] focus entirely on the variable expenses instead of the contribution margins. In the framework of a mobile communications company case study, they report the following expected cost savings, which resulted from a reduction in the rate of returns [32]: "For the [...] device the cost associated to returned and processed units is in the order of $£ 20,700$ (a return rate of
$15.41 \%$ ). If returned rates are reduced to $5 \%$, then the costs associated to returned and processed units is in the order $£$ 6835.90."

The statements in both Speights/Hilinski [31] and Mondragon et al. [32] suggest a linear relation between the rate of returns and the associated costs. However, this assumption is premature for two reasons. First, the authors' deliberations are based on singular, limited planning periods, which limit the cost impact in an undue manner. In fact, every returned item needs to be sold again and then can be sent back yet again [26]. Consequently, the cost impact does not end with the planning period under consideration, but with the final sale. Second, the possibility of deterioration during the revocation period is excluded, which equates to a decline in value from a sales perspective.

A linear understanding of the sales process may be sufficient to successfully determine the contribution margin for a planning period such as in Speights/Hilinski [31]. For returns management tasks that go beyond that, the existing understanding of the process is insufficient for the reasons noted above. Therefore, this article, in contrast to prior publications, examines the issue by means of a circular flow as described in the following section.

To summarize the literature review, there are several conceptual, empirical, and analytical essays regarding the costs of returns. Existing publications provide insights into the returns management process and provide an idea of what returns actually cost. Analytical models build on these observations and improve decision-making with regard to inventory planning as well as selecting the best recovery option. However, there remains a research gap concerning the evaluation of preventive returns management activities. This publication's goal is a better understanding of the cost impact of merchandise returns in mail-ordering to establish a basis for a cost-benefit analysis. It is intended to objectify decisions concerning preventive measures and builds on a 
simple analytical model to determine the number of necessary orders and returns until the final sale, with and without the possibility of product deterioration. Although mathematically savvy readers may argue that some of the following appears trivial, it should be noted that practitioners often neglect and shy away from complex models. Practitioners seek comprehensible and applicable tools and solutions, which this article delivers.

\section{Basic model of a circular sales process and examination of returned goods' cost impact}

The circular model does not end with the revocation if the consumer's expectations are not met. Instead, the item is transported back to the seller, where it is received, processed, and stored. Subsequently, the goods are made available for sale again. The higher the rate of returns $\beta$, the more times an item must process through the cycle, shown in Fig. 2. Therefore, the total costs determined by $\beta$ are depended on the number of times an article is ordered as well as the number of returns until its final sale. To assure a high level of comparability between both models, it will be assumed that each order is composed of a single item.

\subsection{Determining the number of necessary order placements until the final sale}

The probability of a single necessary order until the final sale is $(1-\beta), \beta \cdot(1-\beta)$ for two, $\beta^{2} \cdot(1-\beta)$ for three, and $\beta^{N-1} \cdot(1-\beta)$ for $N$ transactions. It follows implicitly that the average number of necessary orders $\mathrm{NO}(\beta)$ is:

$\mathrm{NO}(\beta)=\sum_{n=1}^{\infty} n \cdot \beta^{n-1} \cdot(1-\beta)=1+\sum_{n=1}^{\infty} \beta^{n}=\sum_{n=0}^{\infty} \beta^{n}$.

$\sum_{n=0}^{\infty} \beta^{n}$ is a convergent geometric series with the individual term $a_{n}=\beta^{n}$ and the common ratio $q=\frac{a_{n+1}}{a_{n}}=\frac{\beta^{n+1}}{\beta^{n}}=\beta$, for which we need to determine the sum by observing the limit:

$\mathrm{NO}(\beta)=\sum_{n=0}^{\infty} \beta^{n}=\lim _{i \rightarrow \infty} \sum_{n=0}^{i} \beta^{n}=\frac{a_{0}}{1-q}=\frac{1}{1-\beta}$.

\subsection{Determining the number of necessary returns until the final sale}

Since the buyer by definition does not return the goods with the final order, one can easily determine the average number of necessary return processes $\mathrm{NR}(\beta)$ :

$$
\begin{aligned}
\mathrm{NR}(\beta) & =\mathrm{NO}(\beta)-1=\frac{1}{1-\beta}-1=\frac{1}{1-\beta}-\frac{1-\beta}{1-\beta} \\
& =\frac{\beta}{1-\beta} .
\end{aligned}
$$

Table 2 shows the quantity of necessary transactions in relation to $\beta$. With the rate of returns set at $50 \%$, the seller must turn the article over to two customers and process one return. In contrast, setting $\beta$ at $70 \%$ leads to 3.33 sales and 2.33 returns processes on average.

\subsection{Relation between the rate of returns and the associated costs to determine the important decision-making parameters}

The resulting costs until an item is sold $C(\beta)$ depend on $\operatorname{NO}(\beta)$ and $\operatorname{NR}(\beta)$ as well as the expense rates $d$ and $r$ :

$$
\begin{aligned}
C(\beta) & =\mathrm{NO}(\beta) \cdot d+\mathrm{NR}(\beta) \cdot r=\frac{1}{1-\beta} \cdot d+\frac{\beta}{1-\beta} \cdot r \\
& =\frac{d+\beta \cdot r}{1-\beta} .
\end{aligned}
$$

Setting the parameter values to $d=\$ 27.50$ and $r=\$ 22.50$, in accordance with the Speights/Hilinski [31] example, creates the cost curve shown in Fig. 3.

The figure visualizes the disproportionate increase in costs that coincides with an increase in the rate of returns $\beta$. The linear relation suggested in Speights/Hilinski [31] or Mondragon et al. [32] becomes untenable.

An item's contribution margin $\mathrm{CM}_{\text {article }}(\beta)$ may now be calculated by subtracting the costs incurred until the item is sold $C(\beta)$ from the trade margin $p-c$ :

$\mathrm{CM}_{\text {article }}(\beta)=p-c-\frac{d+\beta \cdot r}{1-\beta}$.

Comparing Eq. (1) with (6) illustrates the differences in contribution margins on the order and article

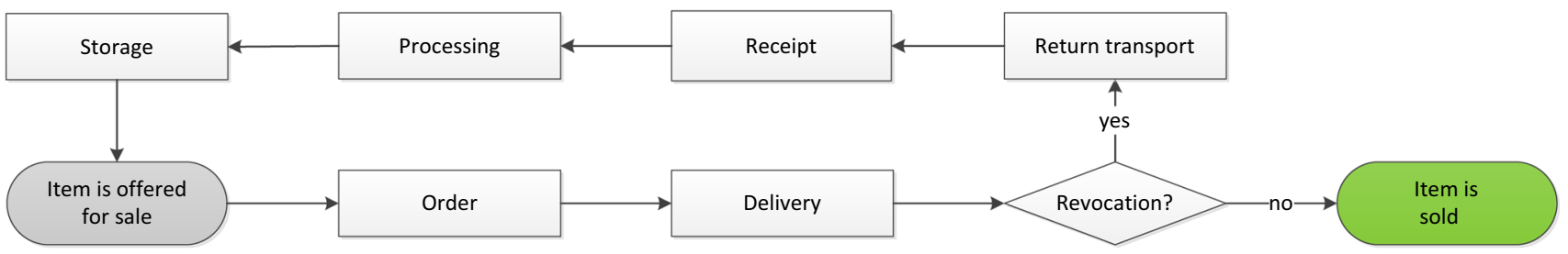

Fig. 2 Circular rendering of the sales process 
Table 2 Expected number of necessary transactions until the final sale of an item

\begin{tabular}{lllllllr}
\hline Rate of returns $\beta$ & $0 \%$ & $20 \%$ & $50 \%$ & $60 \%$ & $70 \%$ & $80 \%$ & $90 \%$ \\
\hline $\mathrm{NO}(\beta)$ & 1 & 1.25 & 2 & 2.5 & 3.33 & 5 & 10 \\
$\mathrm{NR}(\beta)$ & 0 & 0.25 & 1 & 1.5 & 2.33 & 4 & 9 \\
$\mathrm{NO}(\beta)+\mathrm{NR}(\beta)$ & 1 & 1.5 & 3 & 4 & 5.66 & 9 & 19 \\
\hline
\end{tabular}

Fig. 3 Visualization of the returns rate's cost impact regarding the underlying model (linear/circular)

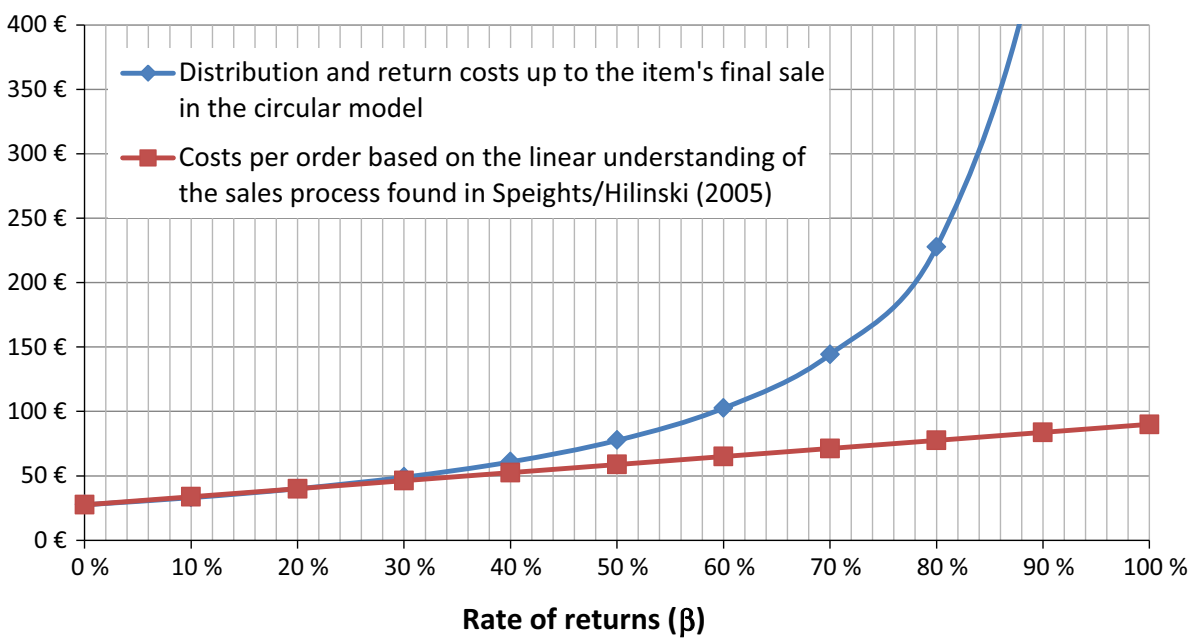

level. The spread results from the revocation rights that may be used not only once but multiple times until an order finally converts into a sale. On average, this process requires $\mathrm{NO}(\beta)$ transactions. Therefore, the relation between the two contribution margins is as follows:

$\mathrm{CM}_{\text {article }}(\beta)=\mathrm{NO}(\beta) \cdot \mathrm{CM}_{\text {order }}(\beta)=\frac{1}{1-\beta} \cdot \mathrm{CM}_{\text {order }}(\beta)$.

It should be noted that Eqs. (1), (6), and (7) describe two overlapping effects. On the one hand, the order-based view underestimates the expenditures subject to the return rate when multiple forward and reverse handling is necessary. On the other hand, the circular sales process represents additional chances to sell the product, which is why the absolute values of article-based margins are higher than the order-based ones.

Additionally, it is useful to determine the $\beta_{\max }$ value required to achieve a positive contribution margin for the business; in other terms, $\mathrm{CM}_{\text {article }}(\beta)>0$ :

$\beta_{\max }<\frac{p-c-d}{p-c+r}$.

Before investing in preventive activities, managers have a reasonable desire to quantify the expected cost effect. If they are able to assess the impact on the returns rate $\Delta \beta$, the percentage change in costs related to merchandise returns $\Delta \mathrm{COST} \%$ is determined as:
$\Delta \operatorname{cosT} \%=\frac{\frac{d+(\beta+\Delta \beta) \cdot r}{1-(\beta+\Delta \beta)}}{\frac{d+\beta \cdot r}{1-\beta}}-1$.

Since certain measures influence not only the cost situation but also the revenue situation, company representatives will particularly want two additional questions answered that pertain to preventive returns management:

- What is the minimum increase required in orders/sales to justify a rise in the rate of returns from $\beta$ to $\beta^{\prime}$ $\left(\beta<\beta^{\prime}\right)$ ?

- To what extent may orders/sales decline to ensure that a reduction in the rate of returns from $\beta$ to $\beta^{\prime}\left(\beta>\beta^{\prime}\right)$ leads to a positive overall effect?

The first question is relevant to decision-makers who are considering liberalizing their returns policy, which commonly accompanies a rise in the rate of returns [33]. The second question mirrors a situation in which managers will soon roll out new measures that will simultaneously reduce the rate of returns while upsetting certain customer groups. Common examples of this are not enclosing a returns voucher, tightening the returns policy, or introducing a restocking fee. To answer these questions, the contribution margins achieved with the different scenarios need to be set in relation to each other. In terms of the percentage change for orders $\triangle \mathrm{ORD} \%$ and sales $\triangle \mathrm{SALE} \%$, this means:

$\Delta \mathrm{ORD} \%=\frac{\mathrm{CM}_{\text {order }}(\beta)}{\mathrm{CM}_{\text {order }}\left(\beta^{\prime}\right)}-1$, 
$\Delta$ SALE $\%=\frac{\operatorname{CM}_{\text {article }}(\beta)}{\operatorname{CM}_{\text {article }}\left(\beta^{\prime}\right)}-1$.

The two effects are interconnected and basically represent two sides of the same coin. Developing (7) shows that:

$\Delta \operatorname{SALE} \%=\left((\Delta \mathrm{ORD} \%+1) \cdot \frac{1-\beta^{\prime}}{1-\beta}\right)-1$.

\subsection{Application of the model in a numerical example}

This chapter ends with an example demonstrating the applicability of the developed formulas. The object of observation is a fashion mail-order retailer. The following parameter values apply to the examined item: $p=89 €$, $c=29 €, d=12 €, r=8 €$. The rate of returns is set to $\beta=50 \%$, a realistic value in the fashion industry [25]. Under these assumed values, the company attains an average unit contribution margin of:

$$
\begin{aligned}
\mathrm{CM}_{\text {article }}(\beta) & =p-c-\frac{d+\beta \cdot r}{1-\beta} \\
& =89 €-29 €-\frac{12 €+0.5 \cdot 8 €}{1-0.5}=28 € .
\end{aligned}
$$

Consequently, the product's retail price floor that breaks even with all else remaining equal is $89 €-28 €=61 €$. Switching to the order perspective, the contribution margin equals:

$$
\begin{aligned}
\mathrm{CM}_{\text {order }}(\beta) & =(1-\beta) \cdot \mathrm{CM}_{\text {article }}(\beta)=(1-0.5) \cdot 28 € \\
& =14 € .
\end{aligned}
$$

In addition, $\beta_{\max }$ signifies the maximum return rate with a positive value contribution:

$$
\begin{aligned}
& \beta_{\max }<\frac{p-c-d}{p-c+r} \\
& \beta_{\max }<\frac{89 €-29 €-12 €}{89 €-29 €+8 €} \\
& \beta_{\max }<0.7059 \\
& \beta_{\max }<70.59 \% .
\end{aligned}
$$

This means that the contribution margin slips into the red as soon as the rate of returns crosses the threshold of roughly $70 \%$.

When assessing the effectiveness of preventive measures, such as improving the instruction manual or adding illustrations, an assumption of the expected effect on the returns rate is required. A decrease by $5 \%$ points, that is $\Delta \beta=-0.05$, leads to:

$$
\begin{aligned}
\Delta \operatorname{COST} \% & =\frac{\frac{d+(\beta+\Delta \beta) \cdot r}{1-(\beta+\Delta \beta)}}{\frac{d+\beta \cdot r}{1-\beta}}-1=\frac{\frac{12+(0.5-0.05) \cdot 8}{1-(0.5-0.05)}}{\frac{12+0.5 .8}{1-0.5}}-1 \\
& =\frac{28.36}{32}-1=-0.1136=-11.36 \% .
\end{aligned}
$$

Consequently, expenditures subject to the product returns rate would decline by $11.36 \%$. The necessary investments should not exceed the expected savings. Other measures, such as aggressively promoting the free returns options, may influence both costs and revenues. On the one hand, this would generate more impulse purchases by lowering reservations regarding ordering. On the other hand, impulse purchases have been known to be returned at a higher rate than usual [34]. In our example, an increase of $5 \%$ points to $\beta^{\prime}=55 \%$ is predicted. The new article and order contribution margins are:

$$
\begin{aligned}
\mathrm{CM}_{\text {article }}\left(\beta^{\prime}\right) & =p-c-\frac{d+\beta^{\prime} \cdot r}{1-\beta^{\prime}} \\
& =89 €-29 €-\frac{12 €+0.55 \cdot 8 €}{1-0.55} \\
& =23.55 €, \\
\mathrm{CM}_{\text {order }}\left(\beta^{\prime}\right) & =p-c-d-\beta^{\prime} \cdot(p-c+r) \\
& =89 €-29 €-12 €-0.55 \cdot(89 €-29 €+8 €) \\
& =10.60 € .
\end{aligned}
$$

Before adopting such a proposal, the expected effect on earnings must be contrasted with the expected effect on costs.

$$
\begin{aligned}
\Delta \text { SALE } \% & =\frac{\mathrm{CM}_{\text {article }}(\beta)}{\mathrm{CM}_{\text {article }}\left(\beta^{\prime}\right)}-1=\frac{28 €}{23.55 €}-1=0.1887 \\
& =18.87 \%, \\
\qquad \mathrm{ORD} \% & =\frac{\mathrm{CM}_{\text {order }}(\beta)}{\mathrm{CM}_{\text {order }}\left(\beta^{\prime}\right)}-1=\frac{14 €}{10.60 €}-1=0.3208 \\
& =32.08 \% .
\end{aligned}
$$

In our example, sales must increase by at least $18.87 \%$ and orders by at least $32.08 \%$ to balance the added costs. If this appears realistic, the proposal should be adopted.

\section{Extending the basic model with the possibility of deterioration}

Until now, this paper has focused on the fundamental connection between the rate of returns and the associated costs. A more realistic portrayal of the sales and return process needs to integrate deterioration, either through usage or during the transportation processes. Therefore, businesses evaluate the item's condition and assign a disposition option. Referring to Norek [19], the model is extended to consider the most important salvaging options, that is, (a) sell as new, (b) repair or repackage and resell as new, and (c) write off and replace the product with a new one after either selling the return to a salvage house or disposing of it (refer to Fig. 4). Therefore, it is necessary to distinguish between A-, B-, and C-returns. 


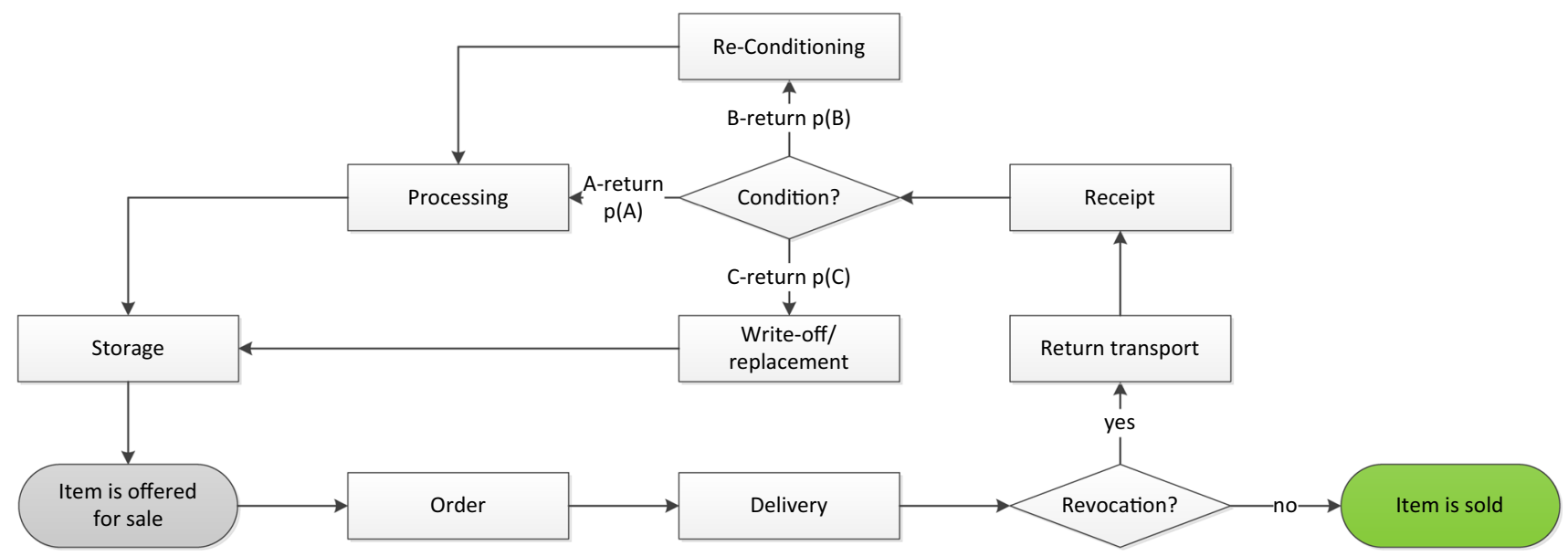

Fig. 4 Circular rendering of the sales process while considering the item condition

A-returns are considered to be in a flawless state and can be resold immediately, which is why merely the base expense rate $r$ is incurred. B-returns require minor work before they can be resold (i.e., changing of the packaging or minor repairs), leading to additional processing expenses $e$. $\mathrm{C}$-returns cannot be reconditioned for sale on the primary market. In this case, the seller must write off the purchase price $c$. Should the vendor be able to sell the goods to a salvage house, this figure will be reduced by the received compensation $m$. However, should the seller be forced to bear waste disposal costs, $m$ will be assigned a negative value. Table 3 summarizes the decision-making process.

\subsection{Model adjustment to consider different item conditions}

Based on this information, the order contribution margin can be calculated in consideration of the heterogeneous item conditions. Building on the base model introduced in the previous section, damages $e$ as well as $c-m$ will be additionally considered with their likelihood of occurrence $p(B)$ and $p(C)$, respectively. Adjusting Eq. (1) leads to:

$$
\begin{aligned}
\mathrm{CM}_{\text {order }}(\beta)= & (1-\beta) \cdot(p-c-d) \\
& -\beta \cdot(r+d+p(B) \cdot e+p(C) \cdot(c-m)) \\
= & p-c-d-\beta \cdot(p-c+r+p(B) \cdot e+p(C) \cdot(c-m)) .
\end{aligned}
$$

Accordingly, the cost factors affected by the rate of returns must be adjusted. Since damages in relation to $p(B)$ and $p(C)$ could occur during each return process, it follows that:

$$
\begin{aligned}
C(\beta)= & \mathrm{NO}(\beta) \cdot d+\mathrm{NR}(\beta) \cdot r+\mathrm{NR}(\beta) \cdot p(B) \cdot e \\
& +\mathrm{NR}(\beta) \cdot p(C) \cdot(c-m) \\
= & \frac{d+\beta \cdot(r+p(B) \cdot e+p(C) \cdot(c-m))}{1-\beta} .
\end{aligned}
$$

Hence, the unit contribution margin changes to:

$$
\begin{aligned}
\mathrm{CM}_{\text {article }}(\beta)= & p-c \\
& -\frac{d+\beta \cdot(r+p(B) \cdot e+p(C) \cdot(c-m))}{1-\beta} .
\end{aligned}
$$

The formula for the maximum return rate that generates a positive contribution margin $\beta_{\max }$ is adapted to:

$\beta_{\max }<\frac{p-c-d}{p-c+r+p(B) \cdot e+p(C) \cdot(c-m)}$.

A final adjustment is required for the percentage change in costs:

$\Delta \operatorname{COST} \%=\frac{\frac{d+(\beta+\Delta \beta) \cdot(r+p(B) \cdot e+p(C) \cdot(c-m))}{1-(\beta+\Delta \beta)}}{\frac{d+\beta \cdot(r+p(B) \cdot e+p(C) \cdot(c-m))}{1-\beta}}-1$.

The equations for $\triangle \mathrm{ORD} \%$ and $\triangle \mathrm{SALE} \%$ remain valid.

\subsection{Integrating different item conditions in the numerical example}

Building on the numerical example introduced in Sect. 3.4, the set parameter values remain valid. However, now, only $90 \%$ of the returns are in a resalable condition. Seven percent show minor damages that can be corrected. This involves average processing costs of $6 €$. Three percent of the returns are sold to a salvage house that pays $5 €$ for each return. This leaves us with $p(A)=0.9, \quad p(B)=0.07, \quad p(C)=0.03, \quad e=6 €, \quad$ and $m=5 €$.

By additionally considering the item condition, the unit contribution equals $26.86 €$ instead of the previous $28 €$ : 
Table 3 Possible item conditions and their economic consequences

\begin{tabular}{llll}
\hline Disposition option & Description & Probabilities $p(A)+p(B)+p(C)=1$ & Additional cost \\
\hline A-return & Indistinguishable from new goods & $p(A)$ & - \\
B-return & Goods with minor damage & $p(B)$ & $e$ \\
C-return & Goods that are no longer sellable & $p(C)$ & $c-m$ \\
\hline
\end{tabular}

$$
\begin{aligned}
\mathrm{CM}_{\text {article }}(\beta)= & p-c-\frac{d+\beta \cdot(r+p(B) \cdot e+p(C) \cdot(c-m))}{1-\beta} \\
= & 89 €-29 € \\
& -\frac{12 €+0.5 \cdot(8 €+0.07 \cdot 6 €+0.03 \cdot(29 €-5 €))}{1-0.5} \\
= & 26.86 € .
\end{aligned}
$$

Hence, deterioration reduces the possible price floor at which the product breaks even. The order contribution margin diminishes from $14 €$ to $13.43 €$ :

$$
\begin{aligned}
\mathrm{CM}_{\text {order }}(\beta) & =(1-\beta) \cdot \mathrm{CM}_{\text {article }}(\beta)=(1-0.5) \cdot 26.86 € \\
& =13.43 € .
\end{aligned}
$$

Similarly, the maximum rate of returns with a positive contribution margin declines to:

$$
\begin{aligned}
& \beta_{\text {max }}<\frac{p-c-d}{p-c+r+p(B) \cdot e+p(C) \cdot(c-m)} \\
& \beta_{\text {max }}<\frac{89 €-29 €-12 €}{89 €-29 €+8 €+0.07 \cdot 6 €+0.03 \cdot(29 €-5 €)} \\
& \beta_{\text {max }}<0.6942 \\
& \beta_{\text {max }}<69.42 \% .
\end{aligned}
$$

Referring to the preventive tasks of returns management, the possibility of deterioration enhances the effect of avoiding and preventing return shipments. A decline of $\beta$ by $5 \%$ points to $45 \%$ would reduce expenditures subject to the returns rate by $13.67 \%$ :

$$
\begin{aligned}
\Delta \operatorname{COST} \% & =\frac{\frac{d+(\beta+\Delta \beta) \cdot(r+p(B) \cdot e+p(C) \cdot(c-m))}{1-(\beta+\Delta \beta)}}{\frac{d+\beta \cdot(r+p(B) \cdot e+p(C) \cdot(c-m))}{1-\beta}}-1 \\
& =\frac{\frac{12+(0.5-0.05) \cdot(8+0.07 \cdot 6 €+0.03 \cdot(29 €-5 €))}{1-(0.5-0.05)}}{\frac{12+0.5 \cdot(8+0.07 \cdot 6 €+0.03 \cdot(29 €-5 €))}{1-0.5}}-1 \\
& =\frac{28.61}{33.14}-1=-0.1367=-13.67 \% .
\end{aligned}
$$

The increase compared to the previously determined $11.36 \%$ justifies higher investments in preventive measures. Beyond that the impact of a free returns promotion needs to be tested under the new conditions. Increasing the rate of returns to $\beta^{\prime}=55 \%$ results in an article and an order contribution margin of:

$$
\begin{aligned}
\mathrm{CM}_{\text {article }}\left(\beta^{\prime}\right)= & p-c-\frac{d+\beta^{\prime} \cdot(r+p(B) \cdot e+p(C) \cdot(c-m))}{1-\beta^{\prime}} \\
= & 89 €-29 € \\
& -\frac{12 €+0.55 \cdot(8 €+0.07 \cdot 6 €+0.03 \cdot(29 €-5 €))}{1-0.55} \\
= & 22.16 €, \\
\mathrm{CM}_{\text {order }}\left(\beta^{\prime}\right)= & p-c-d-\beta^{\prime} \cdot(p-c+r+p(B) \cdot e+p(C) \cdot(c-m)) \\
= & 89 €-29 €-12 €-0.55 \\
& \cdot(89 €-29 €+8 €+0.07 \cdot 6 €+0.03 \cdot(29 €-5 €)) \\
= & 9.97 € .
\end{aligned}
$$

Once again, the expected effect on earnings must be compared with the expected effect on costs.

$$
\begin{aligned}
\Delta \text { SALE } \% & =\frac{\mathrm{CM}_{\text {article }}(\beta)}{\mathrm{CM}_{\text {article }}\left(\beta^{\prime}\right)}-1=\frac{26.86 €}{22.16 €}-1=0.2121 \\
& =21.21 \%, \\
\Delta \mathrm{ORD} \% & =\frac{\mathrm{CM}_{\text {order }}(\beta)}{\mathrm{CM}_{\text {order }}\left(\beta^{\prime}\right)}-1=\frac{13.43 €}{9.97 €}-1=0.3466 \\
& =34.66 \% .
\end{aligned}
$$

The possibility of deterioration leads to additional costs that require more orders and sales to be compensated, making it less likely to have an overall positive impact. Adapting this case shows that once deterioration in the item's condition is considered, the disproportionate increase in costs is further amplified.

\section{Implications of model results}

The presented model leads to a range of theoretical and practical implications. Theoretically, it analyzes the relation between the rate of returns and the costs of returning goods, which is critical for the success of mail-order businesses. In contrast to previous publications, the sales process has been rendered in a circular manner. The model shows that the costs associated with a rise in the rate of returns do not increase linearly, as the results of Speights/ Hilinski [31] or Mondragon et al. [32] imply. Although their order-based approach is well suited to determining the contribution margin for a single period, it obscures the real disproportionate relation. This effect is further amplified by deterioration, either through usage within the revocation 
period or through damages incurred during the logistics processes.

Hence, the article contribution margin differs from the order contribution margin and decreases more lopsidedly as the rate of returns rises. Acknowledging this difference is vital for accurately predicting an item's potential for success, determining its retail price and price floor as well as evaluating the implementation of preventive measures. Therefore, this publication complements the existing range of analytical models, which primarily improved decisionmaking concerning inventory management and product recovery [23-30]. In contrast, this paper objectifies decisions regarding the prevention and avoidance of returns before they actually occur.

Moreover, the developed circular model shows that the product returns should not be viewed as isolated from the forward-directed flow of materials. The more often a product is returned, the more times it has to be ordered and shipped, leading to additional distribution costs.

This finding leads to practical implications. To maximize profits, it is necessary to coordinate the returns management process with traditional corporate functions, particularly with marketing/sales and logistics. Management must ensure that function-specific goals and activities targeting the success of the business are in harmony.

It is understandable that from a marketing perspective, one would want to design the returns process to be as simple and as accommodating as possible. However, market and sales success does not inherently lead to business success. Conversely, excessive focus on costs should also be critically scrutinized because the pursued measures potentially impede additional turnover. Therefore, businesses should target a balanced approach that integrates both sides of the same coin: that is, focusing on customer satisfaction without losing sight of cost-effectiveness. This requires an integrative stance and is closely related to the decision on which preventive measures to adopt. Both avoidance and gatekeeping reduce the number of returns to be processed.

The German fashion retailer Bonprix, for example, adds $3 €$ of store credit to a customer's account for orders that are not returned [35]. According to the model results, the likelihood that these types of avoidance investments will permanently improve operating results increases with the rate of returns. Gatekeeping measures are less popular in business practice because sellers fear the negative influence these may have on customer satisfaction and the generated turnover. Nonetheless, the use of these measures should not be categorically excluded from the realm of possibilities. It is essential to verify whether the reduction in costs associated with the diminished rate of returns can sufficiently compensate for the decline in orders. Only recently, Amazon decided to close several accounts, providing the following justification [36]: “[...] a careful review of this account and related ones shows you've requested refunds and replacements on a majority of your orders for a variety of reasons. In the normal course of business, we expect there may be occasional problems. However, the rate at which such problems have occurred on your account is extraordinary, and it cannot continue. Your Amazon.com account has been closed, and you will no longer be able to shop in our store." Since Amazon is known as an extremely data-driven enterprise, it can be assumed that the pros and cons were thoroughly weighed prior to this decision and that the expected reduction in costs tipped the scales in favor of the suspension of deliveries.

Another takeaway is that the possibility of deterioration amplifies the aforementioned effects. Therefore, distance sellers should work on smart solutions that increase the proportion of A- or B-returns, which may be resold as new after minor rework, to minimize value depreciation. Such an approach can be observed at Amazon. Amazon cooperates with manufacturers to box products in so-called Amazon Certified Frustration-Free Packaging [37]. The packaging benefits consumers because it is easy to open and causes less waste. However, it is also advantageous for Amazon since damaged packaging can be easily replaced, which reduces the quantity of unsellable C-returns.

\section{Conclusions and further research}

This paper introduced a circular model for the sales and returns process in a mail-order context. Geometric series have been used to describe the relation between the rate of returns and related costs. The advantage of this basic model is that even less mathematically savvy practitioners can easily apply it and improve their decision-making by replacing gut feelings with facts.

Referring to the three research questions posed in the beginning, the major lesson learned from this article is that preventive actions play a pivotal role in successfully running a mail-order business. The evaluation of such activities requires (1) estimates regarding a measure's effect on the likelihood of ordering and returning, (2) information about an article's trade margin, and (3) data on the distribution and return costs. The findings suggest that distance sellers with high return rates are very likely to benefit from avoidance and gatekeeping. Such businesses should also reflect upon tightening their returns policies. In contrast, vendors with low return rates should critically review preventive options. Moreover, because of the described disproportionate relation, the latter vendors are often better off loosening their policies, making product returns easier and more convenient for customers. 
Beyond this preventive perspective, the model may also be regarded as a plea to constantly improve merchandise returns handling as it has a direct impact on administrative, processing, and disposition costs. The lower these costs, the less steeply will the cost function subject to the returns rate rise. Therefore, mail-order businesses are strongly recommended to seize every opportunity to streamline internal processes, negotiate lower shipping charges, and improve the product recovery rate. An optimal returns management strategy embraces both preventive measures and the efficient handling of inevitable returns.

Finally, this work should stimulate further research. To deduce conclusions concerning the success potential of the preventive returns management, it is necessary to investigate the specific impact of avoidance and gatekeeping measures. It remains unclear, for example, to what degree the rate of returns is reduced if a business implements same-day delivery instead of a two- to three-day delivery time. To answer these types of questions, in-depth case studies are necessary. From an analytical perspective, model extensions provide the opportunity to investigate follow-up problems. This includes the evaluation of disposition strategies other than those included, such as redistributing returns through stationary trade (i.e., Tchibo Outlets). Another idea would be a model extension that distinguishes costs per item, per order, and per customer and relates to well-known schemes such as activity-based costing.

In closing, we again take on the previously depicted positive development that mail-ordering has experienced. In the past, market players were able to win over a significant sales volume that had once belonged to the stationary trade. Currently, there appears to be no solid arguments for why this development will be reversed. The positive picture is tarnished by the fact that consumer-friendly return policies have led to an increase in the rate of returns, a trend that is expected to continue [21]. This article can be viewed as a general plea not to lose sight of the return costs while addressing future growth. Only then can survival and competitiveness be permanently guaranteed. A forceful implementation of the analytical decision-making aids developed in this article will contribute to the affected retailers' ability to achieve profitable growth in a sustainable manner.

Acknowledgments The author would like to thank the two anonymous reviewers for their helpful and constructive comments that contributed to improving the final version of the paper.

Open Access This article is distributed under the terms of the Creative Commons Attribution 4.0 International License (http://crea tivecommons.org/licenses/by/4.0/), which permits unrestricted use, distribution, and reproduction in any medium, provided you give appropriate credit to the original author(s) and the source, provide a link to the Creative Commons license, and indicate if changes were made.

\section{References}

1. BEVH (2014) Aktuelle Zahlen zum Interaktiven Handel. http:// www.bevh.org/markt-statistik/zahlen-fakten/. Accessed 31 Oct 2014

2. O'Neill S, Chu J (2001) Online returns management strategies. IBM Global Service eStrategy Report

3. Mollenkopf DA, Rabinovic E, Laseter TM, Boyer KK (2007) Managing internet product returns: a focus on effective service operations. Decis Sci 38:215-239

4. Petersen JA, Kumar V (2009) Are product returns a necessary evil? Antecedents and consequences. J Mark 73:35-51

5. Shulman JD, Coughlan AT, Savaskan RC (2009) Optimal restocking fees and information provision in an integrated demand-supply model of product returns. Manuf Serv Oper Manag 11:577-594

6. Davis S, Gerstner E, Hagerty M (1998) Return policies and the optimal level of "Hassle". J Econ Bus 50:445-460

7. Davis S, Gerstner E, Hagerty M (1995) Money back guarantees in retailing: matching products to consumer tastes. J Retail 71:7-22

8. Anderson ET, Hansen K, Simester D (2009) The option value of returns: theory and empirical evidence. Mark Sci 28:405-423

9. State of California Department of Justice (2015) Refund policies. http://oag.ca.gov/consumers/general/refund_policies. Accessed 15 Apr 2015

10. The Office of the Revisor of Statutes (2015) Retail sales of consumer goods; refunds. https://www.revisor.leg.state.mn.us/ statutes/?id=325F.80\&year=2014. Accessed 15 Apr 2015

11. European Union (2015) Returning unwanted goods. http://europa. eu/youreurope/citizens/shopping/shopping-abroad/returningunwanted-goods/index_en.htm. Accessed 22 Apr 2015

12. Rogers DS, Lambert DM, Croxton KL, García-Dastugue SJ (2002) The returns management process. Int J Log Manag 13:1-18

13. Asdecker B (2011) Retourenmanagement-Eine Literaturrecherche. In: Sucky E, Asdecker B, Dobhan A, Haas S, Wiese J (eds) Logistikmanagement-Herausforderungen, Chancen und Lösungen Band II, University of Bamberg Press, Bamberg, pp 421-461

14. Johnson JR (2005) Waging war on returns. DC Veloc 3:25-28

15. Stock JR, Mulki JP (2009) Product returns processing: an examination of practices of manufacturers, wholesalers/distributors, and retailers. J Bus Log 30:33-62

16. Sproov (2015) sproov's size recommender-the B2B solution for your high return rates. http://www.sproov.com/. Accessed $10 \mathrm{Apr}$ 2015

17. Lunden I (2015) Amazon quietly acquired Shoefitr to improve how it sells footware online. http://techcrunch.com/2015/04/10/ amazon-quietly-acquired-shoefitr-to-improve-how-it-sells-foot wear-online/. Accessed 14 Apr 2015

18. Stock JR, Speh T, Shear H (2006) Managing product returns for competitive advantage. MIT Sloan Manag Rev 48:57-62

19. Norek CD (2003) Throwing it into reverse. DC Veloc 1:54-58

20. Blackburn JD, Guide VDR Jr, Souza GC, Van Wassenhove LN (2004) Reverse supply chains for commercial returns. Calif Manag Rev 46:6-22

21. ibi Research (2013) Retourenmanagement im online-handelDas Beste draus machen. Regensburg

22. Asdecker B, Weigel A (2013) Der Missbrauch des Widerrufsrechts aus Sicht des deutschen Onlinehandels. eStrategy Mag 13:8-11

23. Fleischmann M, Kuik R, Dekker R (2002) Controlling inventories with stochastic item returns: a basic model. Eur J Oper Res 138:63-78 
24. Vlachos D, Dekker R (2003) Return handling options and order quantities for single period products. Eur J Oper Res 138:38-52

25. Mostard J, Teunter R (2006) The newsboy problem with resalable returns: a single period model and case study. Eur J Oper Res 169:81-96

26. Mostard J, de Koster R, Teunter R (2005) The distribution-free newsboy problem with resalable returns. Int $\mathrm{J}$ Prod Econ 97:329-342

27. Chen J, Bell PC (2009) The impact of customer returns on pricing and order decisions. Int J Oper Res 195:280-295

28. Kiesmüller GP, Minner S, Kleber R (2004) Managing dynamic product recovery: an optimal control perspective. In: Dekker R, Fleischmann M, Inderfurth K, Van Wassenhove LN (eds) Reverse logistics-quantitative models for closed-loop supply chains. Springer, Berlin, pp 221-247

29. Das K, Chowdhury AH (2012) Designing a reverse logistics network for optional collection, recovery and quality-based product-mix planning. Int J Prod Econ 135:209-221

30. Johnson MR, McCarthy IP (2014) Product recovery decisions within the context of extended producer responsibility. J Eng Technol Manag 34:9-28
31. Speights D, Hilinski M (2005) Return fraud and abuse: how to protect profits. Ret Issues Lett 17:1-6

32. Mondragon AEC, Lalwani C, Mondragon CEC (2011) Measures for auditing performance and integration in closed-loop supply chains. Supply Chain Manag Int J 16:43-56

33. Wood S (2001) Remote purchase environments: the influence of return policy leniency on two-stage decision processes. J Mark Res 38:157-169

34. Bechwati NN, Siegal WS (2005) The impact of the prechoice process on product returns. J Mark Res 42:358-367

35. Bonprix (2014) $3 €$ Retourenbonus. http://www.bonprix.de/ser vice/gutschein/retourbonus/. Accessed 23 Sept 2014

36. Amazon (2014) Amazon.com general help forum. http://www. amazon.com/gp/help/customer/forums/ref=help_forum_tft_tp?ie $=\mathrm{UTF} 8 \& \mathrm{cdF}$ orum $=$ Fx 2NFGOONPZEXIP $\&$ cdThread $=$ Tx $1 \mathrm{IS} 0 \mathrm{~V}$ NGMKXPXQ. Accessed 01 Nov 2014

37. Amazon (2015) Amazon frustration-free packaging. http://www. amazon.com/b/?\&node=5521637011. Accessed 03 June 2015 